\title{
ESTADO DA ARTE DO COMPORTAMENTO HIDROLÓGICO DE TELHADOS VERDES NO BRASIL: UMA REVISÃO SISTEMÁTICA
}

\section{STATE OF THE ART OF HYDROLOGICAL BEHAVIOR OF GREEN ROOFS IN BRAZIL: A SYSTEMATIC REVIEW}

\author{
Bruna Vogt Bär 1 \\ Universidade Federal do Paraná, Curitiba, PR, Brasil, bruna.vogt@outlook.com
}

Sergio Fernando Tavares ${ }^{2}$

Universidade Federal do Paraná, Curitiba, PR, Brasil, sergioft22@yahoo.com.br

\begin{abstract}
Resumo
Esta revisão sistemática aborda o comportamento quantitativo e qualitativo das águas escoadas por telhados verdes, com o objetivo de levantar-se o estado da arte dessa área de estudo em um cenário brasileiro. Para isso, optou-se por selecionar a maior quantidade e variedade de materiais disponíveis possível, dentro dos critérios de elegibilidade. Pesquisas nas bases de dados Banco de Teses e Dissertações da CAPES, Google Acadêmico e SciELO, juntamente com o acréscimo de literaturas cinzentas, resultaram em um total de 40 materiais acadêmicos selecionados. A partir desses, observa-se que a diversidade de abordagens, e a diferença entre os componentes dos telhados verdes utilizados pelos autores, dificultam uma comparação e agrupamento dos resultados obtidos. Entretanto, vários trabalhos referentes à capacidade de retenção de águas pluviais apresentam conclusões concordantes, como a influência da inclinação, umidade, período de intervalos entre precipitações e características da precipitação. Já para os trabalhos referentes à qualidade das águas escoadas por essas coberturas, os resultados são bastante variantes e até mesmo contraditórios. Entretanto, de um modo geral, concorda-se que a camada de substrato e a de vegetação tendem a liberar maiores concentrações de substâncias, como fósforo, nitrogênio, ferro e nitrito; e podem ainda diminuir a qualidade da água escoada, resultado da decomposição de matéria orgânica nesses sistemas. Por fim, esta revisão destaca a necessidade de maiores estudos quanto ao desempenho hidrológico de telhados verdes, e sua influência em sistemas de drenagem urbana. Também se observa que métodos de pesquisa padronizados poderiam auxiliar a compatibilização de resultados, e poderiam contribuir de maneira positiva na construção de uma evidência cientifica eficaz da adaptação e desempenho dessas coberturas para regiões brasileiras.
\end{abstract}

Palavras-chave: Escoamento. Retenção pluvial. Coberturas verdes. Qualidade das águas.

\begin{abstract}
This systematic literature review addresses the quantitative and qualitative behavior of the waters drained by green roofs, aiming to raise the state of the art of this area of study to a Brazilian scenario. To do this, we chose to select the significant quantity and variety of materials available, within the eligibility criteria. Searches in the databases of Thesis and Dissertation of CAPES, Google Academic, and SciELO, together with the addition of gray literature, resulted in 40 selected references. From these, it is observed that the diversity of approaches, and the difference between the components of the green roofs used by the authors, makes it difficult to compare and group the results obtained. However, several works related to rainwater retention capacity have accordant conclusions, such as the influence of slope, humidity, the period of intervals between precipitations and characteristics of precipitation. Regarding the quality of the water drained by these coverages, the results are quite variant and even contradictory. However, in general, it is agreed that the substrate and vegetation layers tend to release higher concentrations of substances, such as phosphorus, nitrogen, iron, and nitrite, and may decrease the quality of the drained water, as a result of the decomposition of organic matter in these systems. Finally, this review highlights the need for further studies on the hydrological performance of green roofs, and their influence on urban drainage systems. It is also observed that standardized research methods could help the compatibilization of results, and could contribute positively to the construction of compelling scientific evidence of the adaptation and performance of these coverages for Brazilian regions.
\end{abstract}

Keywords: Runoff. Rain retention. Green roofs. Water quality.

How to cite this article:

BÄR, Bruna Vogt; TAVARES, Sergio Fernando. Estado da arte do comportamento hidrológico de telhados verdes no brasil: uma revisão sistemática. PARC Pesquisa em Arquitetura e Construção, Campinas, SP, v. 8, n. 4, p. 257-271, dez. 2017. ISSN 1980-6809. Disponível em: $<$ <ttps://periodicos.sbu.unicamp.br/ojs/index.php/parc/article/view/8650106>. Acesso em: 22 fev. 2018.

doi:https://doi.org/10.20396/parc.v8i4.8650106. 


\section{Introdução}

Segundo Alexandri e Jones (2008), a humanidade tem, desde seus primeiros traços, insistido em alterar seu ambiente de convívio para um ambiente mais "humanoamigável", ou seja, um ambiente construído para sua segurança e proteção. Com a evolução e estabilização das sociedades, vilas e cidades foram tomando conta dos espaços disponíveis, em função de suas disposições geográficas, econômicas e sociais. Após a Revolução Industrial, os espaços urbanos apresentaram um crescimento drasticamente maior e mais rápido, com maiores mudanças ambientais que seus períodos anteriores. A falta de vegetação em áreas urbanas apresenta um efeito direto nas condições locais, principalmente em centros e metrópoles, gerando problemas ambientais.

Um dos fatores determinantes para a ocorrência de inundações é a interferência da permeabilidade da água do solo. Grandes áreas asfaltadas, superfícies cimentadas, ou sistemas de drenagem deficientes são grandes empecilhos ao escoamento superficial da água. Esses fatores, somados a períodos de precipitação intensa, podem ocasionar alagamentos e acúmulos de água localizados, podendo gerar graves consequências para o bem-estar humano (BRASIL, 2013). Práticas tradicionais de drenagem urbana direcionam as águas pluviais escoadas diretamente para os corpos de água naturais locais. Telhados verdes, por sua vez, são projetados para capturar, reter e utilizar as águas pluviais, através de evaporação, evapotranspiração e reuso dessas águas. Tal técnica é capaz de reduzir e atenuar os efeitos das águas de escoamento em áreas urbanas (LAMERA et al., 2014).

Berardi, Ghaffarianhoseini e Ghaffarianhoseini (2014) abordam a questão de legislações para telhados verdes, que tem ganho papel mundial com o intuito de encorajar edificações mais sustentáveis. A adoção de telhados verdes melhora o comportamento térmico de ambientes internos (MONTANARI; LABAKI, 2017) e colabora para a biodiversidade urbana (MENDONÇA, 2015; MENDONÇA; MELO, 2017). Algumas cidades brasileiras já têm adotado projetos de lei que promovem o uso de telhados verdes em novas edificações, como Rio de Janeiro, com a Lei 6.349/2012, Recife, com a aprovação da lei 18.112/2015, e Curitiba, com o projeto de Lei $n^{\circ}$ 005.00006.2013.

A partir deste cenário, é evidente a urgência no desenvolvimento de conhecimento e sistemas de telhados verdes funcionais para regiões brasileiras, inclusive para que novas leis possam ser implementadas e cumpridas satisfatoriamente, tanto em um nível de sustentabilidade, como em um nível de satisfação de usuários. Assim, esta revisão sistemática visa o levantamento do estado da arte referente a estudos acadêmicos sobre o comportamento hidrológico de telhados verdes, em um cenário brasileiro. Neste contexto, estipula-se que o comportamento hidrológico engloba o comportamento de telhados verdes em relação à quantidade e qualidade das águas pluviais que são escoadas por esses sistemas.

\section{Fundamentação}

Telhados verdes são usualmente divididos em três tipos: (i) intensivo; (ii) extensivo; (iii) e semi-intensivo. Essa classificação afeta diretamente na determinação de que tipos de vegetação serão utilizados, e o cenário final da construção. Telhados verdes intensivos são caracterizados por uma camada de substrato maior que das outras duas classificações. Por esse motivo, esse sistema é capaz de suportar vegetações maiores, arbustos e até mesmo, eventualmente, árvores. Entretanto, demanda manutenção intensa e constante. Já os telhados verdes extensivos são caracterizados por uma camada pequena de substrato, limitando ao uso de vegetações rasteiras e de pequeno porte. Não necessita de manutenção, contudo, eventuais regas e fertilizações podem vir a serem necessárias. Por fim, telhados verdes semi-intensivos são caracterizados entre um meio termo entre os outros dois sistemas. Não necessitam da mesma intensidade de manutenção que telhados intensivos, mas não estão tão isentos desta, como telhados extensivos (FLL, 2002).

De acordo com Vijayaraghavan (2016), dependendo do local a serem construídos, e dos resultados pretendidos, telhados verdes podem englobar uma série de camadas componentes, conforme ilustrado na Figura 1.

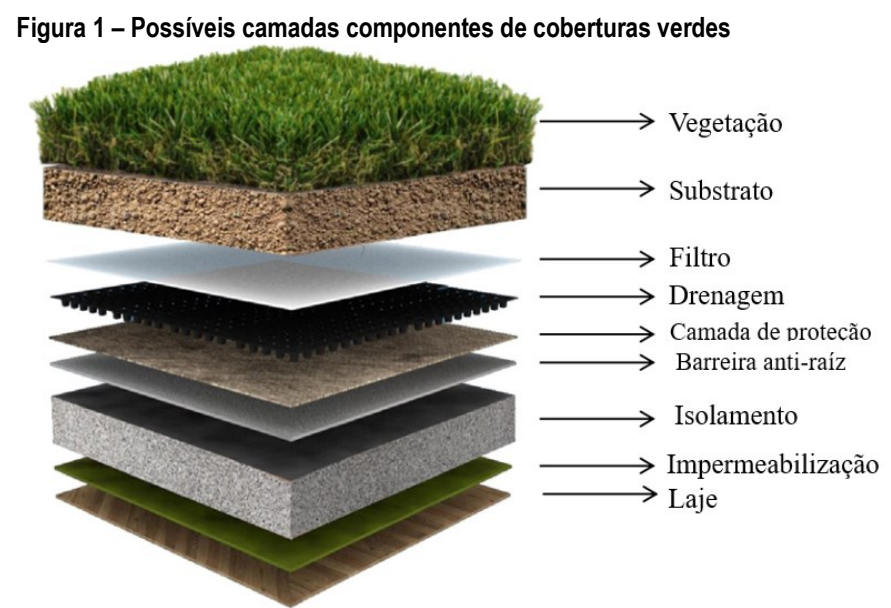

Fonte: Adaptado de Vijayaraghavan (2016).

Para que telhados verdes sejam uma solução sustentável e também capazes de atender às expectativas de seus usuários, a seleção eficiente de materiais é de vital importância (VIJAYARAGHAVAN, 2016). 


\section{Método}

Para o desenvolvimento desta revisão sistemática foram utilizadas as recomendações apresentadas pelo método PRISMA (MOHER et al., 2015). Esse método consiste em um checklist com recomendação de itens a serem incluídos na revisão sistemática, e um fluxograma ilustrando a seleção dos estudos levantados. Os critérios sugeridos foram utilizados para a delimitação e condução desta revisão, e são abordados nos próximos itens a seguir.

\section{Critérios de elegibilidade de estudos}

Para a seleção de estudos, buscou-se trabalhos sobre telhados verdes que levassem em consideração o desempenho hidrológico do sistema (retenção de escoamento e qualidade das águas escoadas). Trabalhos referentes a esse tipo de cobertura que não mencionassem esse tipo de desempenho do sistema não foram selecionados. Uma vez que essa revisão não busca atualizar nenhuma outra revisão anterior, nenhuma limitação temporal foi utilizada, com o intuito de abranger a maior quantidade de materiais possíveis.

Para esta revisão, discutem-se os seguintes problemas:

(i) Qual é o estado da arte brasileiro referente aos trabalhos acadêmicos e científicos que abordem o comportamento hidrológico de coberturas verdes?

(ii) Quais as formas de abordagens utilizadas por esses trabalhos?

(iii) Quais os resultados obtidos, até o momento, por esses estudos?

Para responder a essas questões, buscou-se selecionar a maior variedade e quantidade possível de materiais bibliográficos (dentro do contexto avaliado), e a partir da leitura e análise destes encontrar características ou similaridades nos métodos de pesquisa empregados para a condução dos estudos, nos resultados, ou nos assuntos estudados. A partir dessa análise, foi possível dividir os materiais selecionados nos seguintes tópicos: (i) capacidade de armazenamento de águas pluviais; (ii) atraso do escoamento pluvial; (iii) qualidade das águas escoadas, (iv) características e composição do substrato, e (v) simulações de implementação.

\section{Fontes de informação}

Para o levantamento de matérias literárias, as plataformas de busca utilizadas foram: Banco de Teses e Dissertações da CAPES, Google Acadêmico e SciELO. A última busca de materiais foi realizada no dia 19 de julho de 2017.

\section{Busca}

Os termos utilizados para pesquisa foram "telhado verde" e "cobertura verde". Nenhuma restrição de data, tipo de material ou idioma foi aplicada para as plataformas de busca Banco de Teses e Dissertações da CAPES e SciELO. Para a plataforma de busca Google Acadêmico utilizou-se a limitação de palavras chaves para serem inclusas no título, além disso, citações e patentes foram desconsideradas.

Destaca-se aqui a dificuldade de buscas de materiais brasileiros em plataformas específicas para este uso. Por exemplo: ao realizarem-se buscas com os termos "verde + escoamento" nas mesmas plataformas citadas anteriormente, nenhum resultado é encontrado. Entretanto, 10 dos trabalhos selecionados para esta revisão possuem essas duas palavras em seus títulos. Além disso, ainda não se apresenta um termo padrão em português que simbolize estudos de comportamento hidrológico em telhados verdes. Na língua inglesa, por exemplo, o termo runoff tem sido utilizado como referência padrão para esse tipo de estudo.

\section{Seleção de estudos}

Uma seleção prévia foi realizada a partir da leitura do título e resumo do material para cada plataforma de busca. A partir dessa pré-seleção excluiu-se trabalhos repetidos ou trabalhos que não foram possíveis de serem obtidos pelo endereço eletrônico de divulgação. Após uma revisão mais aprofundada do conteúdo dos materiais préselecionados, trabalhos que não atendessem aos critérios de elegibilidade, mais uma vez, foram descartados. Optouse por incluir todos os tipos de trabalhos acadêmicos (trabalhos de conclusão de curso, dissertações, teses e artigos) nesta revisão, para obter-se maior abrangência de estudos.

\section{Resultados e discussão}

\section{Materiais selecionados}

Obteve-se um total de 223 resultados identificados ao realizar-se as buscas descritas anteriormente. A esses resultados, optou-se por acrescentar mais 12 materiais obtidos por outras fontes e pesquisas (literatura cinzenta). Segundo Brasil (2012), literatura cinzenta é constituída de artigos elegíveis (para uma revisão sistemática ou metanálise) e que podem não ter sido recuperados pela estratégia de busca. Uma das maneiras de obter-se esses materiais é através da verificação de Referências Bibliográficas de estudos incluídos na revisão ou em buscas prévias de material. A literatura cinzenta selecionada para esta revisão foi obtida através de arquivos digitais, dos quais os autores já possuíam antes das buscas para esta revisão sistemática, mas que, por algum motivo, não foram recuperadas nas buscas realizadas. Alguns dos materiais selecionados não estavam disponíveis on-line, e em um caso, o endereço eletrônico estava fora do ar, não conseguindo obter-se acesso a estes. Em alguns casos, 
mais que um dos materiais se referia ao mesmo estudo. Nesses, optou-se por agrupar esses materiais, para não haver repetição de informações. O processo de seleção de materiais para esta revisão sistemática é ilustrado na Figura 2. Já o Quadro 1 apresenta a distribuição dos estudos efetivos nos tópicos abordados por esta revisão.

Figura 2 - Fluxograma de seleção de materiais para a revisão sistemática

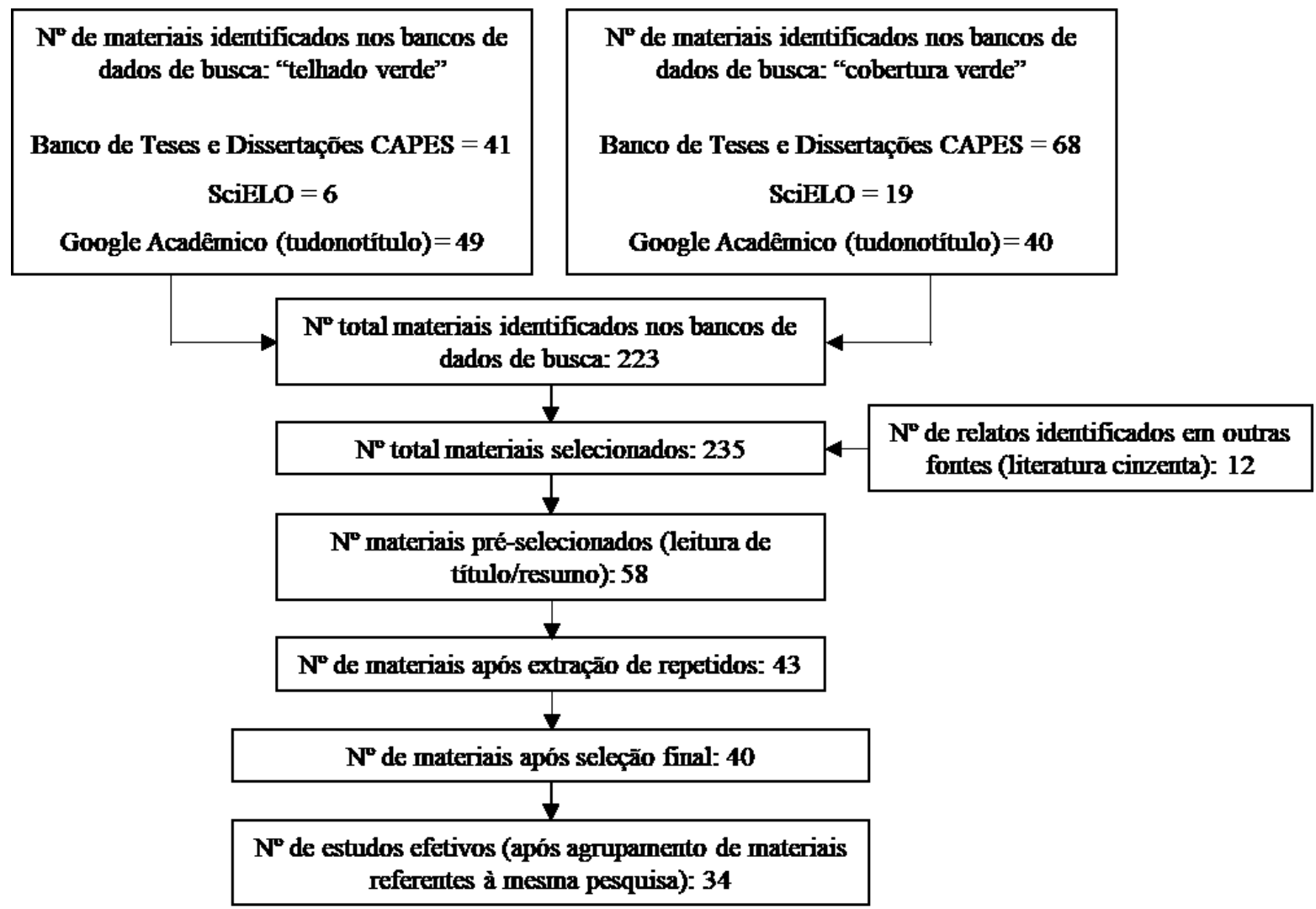

Fonte: Os autores

\begin{tabular}{l} 
Quadro 1 - Distribuição dos estudos efetivos identificados nos tópicos da revisão sistemática da literatura desenvolvida \\
\begin{tabular}{|c|c|}
\hline Tópicos estudados & Estudos identificados \\
\hline Capacidade de armazenamento de águas pluviais & $\begin{array}{c}\text { Araújo et al. (2013), Araújo et al. (2014), Bacovis e Nagalli (2013), Baldessar (2012), Castro (2014), } \\
\text { Castro e Goldenfum (2008), Castro e Goldenfum (2010), Costa, Poleto e Ramme (2016), Ferreira } \\
(2015), \text { Jobim (2013), Klein (2017), Louzada (2016), Martins e Pinto (2016), Mendonça (2015), Miller } \\
\text { (2014), Moruzzi, Moura e Barbassa (2014), Moura (2012), Nascimento (2015), Ohnuma, Halasz e } \\
\text { Mendiondo (2011), Oliveira (2009), Pessoa (2016), Santos (2011), Santos et al. (2013), Savi (2015), } \\
\text { Silva, Paiva e Santos (2015), Tassi et al. (2013) e Vacari (2015) }\end{array}$ \\
\hline Atraso do escoamento pluvial; & $\begin{array}{c}\text { Costa, Costa e Poleto (2012), Costa, Poleto e Ramme (2016), Louzada (2016), Nascimento (2015), } \\
\text { Oliveira (2009), Santos et al. (2013) e Santos (2011) }\end{array}$ \\
\hline Qualidade das águas escoadas & $\begin{array}{c}\text { Basso (2013), Budel (2014), Castro (2014), Castro e Goldenfum (2008), Castro e Goldenfum (2010), } \\
\text { Ferreira (2015), Klein (2017), Moruzzi, Moura e Barbassa (2014), Moura (2012), Pessoa (2016), Savi } \\
\text { (2015), Teixeira et al (2017) e Vacari (2015) }\end{array}$ \\
\hline Características e composição do substrato & Garcia et al. (2015), Magalhães (2015), Oliveira (2012) e Willes (2014) \\
\hline Simulações de implementação & Alamy Filho et al. (2016), Calil, Bernardi e Righes (2014), Garrido Neto (2016), Leite, Fujimura e \\
Fernandes (2016) e Vieira, Silva Jr. e Ribeiro (2015),
\end{tabular} \\
\hline
\end{tabular}

Fonte: Os autores.

\section{Capacidade de armazenamento de águas pluviais}

Segundo Berndtsson (2010), telhados verdes armazenam a água pluvial que adentra seu sistema e atrasam o pico do seu escoamento (Figura 3), comparando com coberturas tradicionais. Isso acontece devido a retenção de volume de água pelas camadas do telhado verde. A água retida é evaporada ou utilizada pelas plantas para seu processo de fotossíntese. A combinação desses dois processos é chamada de foto transpiração, e é este fenômeno que explica a redução do volume de água escoada por telhados verdes. Os processos hidrológicos de telhados verdes são ilustrados na Figura 4.

As pesquisas identificadas para esta seção são experimentos de monitoramento realizados através de simulações de precipitação ou de eventos naturais de chuva. A comparação de valores de redução de 
escoamento obtidos por diferentes estudos se torna difícil por causa da diversidade de métodos e abordagens utilizados, e também, pela diferença dos componentes utilizados entre os telhados verdes testados.

Essa dificuldade também é observada por Berndtsson (2010). Os principais resultados levantados por essa sistematização de estudos são apresentados nas Tabelas 1

Figura 3 - Ilustração de escoamento (linha tracejada) gerado por precipitação (linha preta)

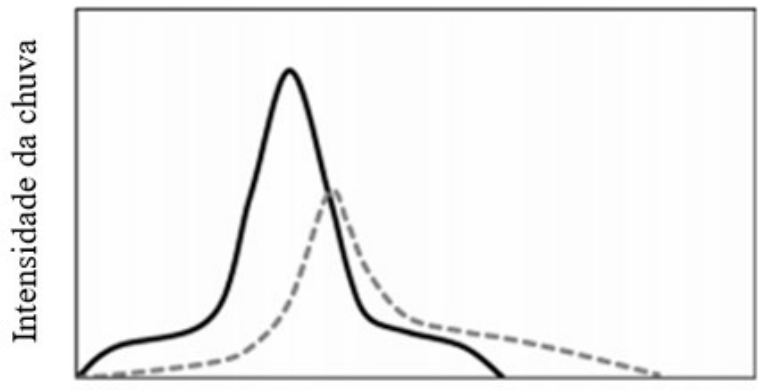

Tempo

Fonte: Adaptado de Berndtsson (2010). e 2. Trabalhos que não apresentaram valores sobre a quantidade de precipitação retida observada, como no caso de Costa, Costa e Poleto (2012), não foram considerados.

A partir da leitura dos materiais selecionados, observa-se que o potencial de retenção de águas pluviais por telhados verdes está correlacionado à uma série de fatores internos e externos ao sistema de cobertura.

Figura 4 - Processos hidrológicos de telhados verdes

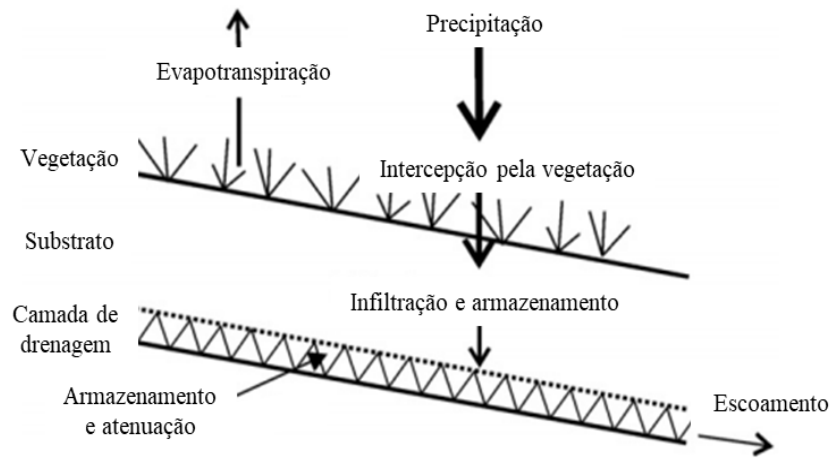

Fonte: Adaptado de Stovin, Vesuviano e Kasmin (2012)

Tabela 1 - Valores de retenção apresentados pelos estudos selecionados - eventos de precipitação simulados

\begin{tabular}{|c|c|c|c|c|c|c|c|}
\hline Autores & $i \%$ & $\begin{array}{c}\text { Qtd. } \\
\text { eventos }\end{array}$ & $\begin{array}{l}\text { Intensidade } \\
\text { da chuva }\end{array}$ & $\begin{array}{c}\text { Duração } \\
\text { chuva }\end{array}$ & Distinção do telhado & $\begin{array}{l}\text { Retenção do } \\
\text { escoamento }\end{array}$ & Local \\
\hline Oliveira (2009) & $6 \%$ & 2 & $\begin{array}{l}8,77 \mathrm{~mm} / \mathrm{h} \\
42 \mathrm{~mm} / \mathrm{h}\end{array}$ & $13 \mathrm{~min}$ & $\begin{array}{l}\text { TV simulação } 1 \\
\text { TV simulação } 2\end{array}$ & $\begin{array}{l}55 \% \\
56 \%\end{array}$ & $\begin{array}{c}\text { Vargem Grande } \\
\text { Paulista - PS }\end{array}$ \\
\hline $\begin{array}{l}\text { Santos et al. (2013), e } \\
\text { Santos (2011) }\end{array}$ & n.i. ${ }^{1}$ & 2 & $\begin{array}{l}42 \mathrm{~mm} / \mathrm{h} \\
42 \mathrm{~mm} / \mathrm{h} \\
79 \mathrm{~mm} / \mathrm{h} \\
79 \mathrm{~mm} / \mathrm{h}\end{array}$ & $30 \mathrm{~min}$ & $\begin{array}{l}\text { TV com grama } \\
\text { TV com cactos } \\
\text { TV com grama } \\
\text { TV com cactos }\end{array}$ & $\begin{array}{l}33,6 \% \\
32,1 \% \\
15,5 \% \\
14,2 \%\end{array}$ & Caruaru - PE \\
\hline $\begin{array}{l}\text { Moura (2012) e Moruzzi, } \\
\text { Moura e Barbassa (2014) }\end{array}$ & $\begin{array}{l}10 \% \\
20 \% \\
30 \% \\
\end{array}$ & 14 & $\begin{array}{c}\text { de } 81,2 \text { à } \\
117,7 \mathrm{~mm} \cdot \mathrm{h}^{-1}\end{array}$ & $30 \mathrm{~min}$ & $\begin{array}{l}\text { TV inclinação 10\% } \\
\text { TV inclinação } 20 \% \\
\text { TV inclinação } 30 \%\end{array}$ & $\begin{array}{c}11,6 \pm 1,4 \mathrm{~mm} \\
10,0 \pm 1,2 \mathrm{~mm} \\
9,5 \pm 1,1 \mathrm{~mm} \\
\end{array}$ & Rio Claro - SP \\
\hline Bacovis e Nagalli (2013) & $5 \%$ & 4 & $43,6 \mathrm{~mm}$ & $16 \min$ & $\begin{array}{c}\text { TV seco } \\
\text { TV semi saturado } \\
\text { TV saturado }\end{array}$ & $\begin{array}{c}22 \% \\
10 \% \\
1 \% \\
\end{array}$ & Curitiba - PR \\
\hline $\begin{array}{c}\text { Silva, Paiva e Santos } \\
(2015)\end{array}$ & n.i. & 1 & $74,21 \mathrm{~mm} / \mathrm{h}$ & $58 \mathrm{~min}$ & $\begin{array}{c}\text { TV com Babosa } \\
\text { TV com coroa-de-frade }\end{array}$ & $\begin{array}{l}77 \% \\
98 \%\end{array}$ & Caruaru - PE \\
\hline Nascimento (2015) & $6 \%$ & 24 & $155 \mathrm{~mm} / \mathrm{h}$ & $7 \mathrm{~min}$ & $\begin{array}{l}\text { TV seco sem vegetação } \\
\text { TV seco com vegetação } \\
\text { TV úmido sem vegetação } \\
\text { TV úmido com vegetação } \\
\text { Média geral telhado com vegetação } \\
\text { Média geral telhado sem vegetação }\end{array}$ & $\begin{array}{c}70,99 \% \\
72,99 \% \\
56,04 \% \\
33,3 \% \\
53,14 \% \\
63,52 \% \\
\end{array}$ & $\begin{array}{c}\text { Rio de Janeiro - } \\
\text { RJ }\end{array}$ \\
\hline Louzada (2016) & $\begin{array}{l}2 \% \\
20 \%\end{array}$ & 4 & $\begin{array}{c}\text { de } 37,6 \text { à } \\
65,40 \mathrm{~mm} / \mathrm{h}\end{array}$ & $\begin{array}{c}20 \text { e } 30 \\
\min \end{array}$ & $\begin{array}{l}\text { Módulo de controle i } 2 \% \\
\text { Módulo vegetado geomanta i2\% } \\
\text { Módulo vegetado geotêxtil i2\% } \\
\text { Módulo de controle i15\% } \\
\text { Módulo vegetado geomanta i15\% } \\
\text { Módulo vegetado geotêxtil i15\% }\end{array}$ & $\begin{array}{c}8,8 \% \\
64,9 \% \\
93,4 \% \\
6,8 \% \\
47,1 \% \\
86,5 \% \\
\end{array}$ & Natal - RN \\
\hline $\begin{array}{l}\text { Costa, Poleto e Ramme } \\
\text { (2016) }\end{array}$ & $15 \%$ & n.i. & n.i. & $5 \mathrm{~min}$ & Telhado verde & Até $26 \%$ & Toledo - PR \\
\hline
\end{tabular}




\begin{tabular}{|c|c|c|c|c|c|}
\hline Autores & i & $\begin{array}{l}\text { Tempo de } \\
\text { monitoramento }\end{array}$ & Distinção do telhado & $\begin{array}{l}\text { Valor de retenção } \\
\text { do escoamento }\end{array}$ & Local do experimento \\
\hline Castro e Goldenfum (2010) & $\begin{array}{l}0^{\circ} \mathrm{e} \\
15^{\circ}\end{array}$ & $\begin{array}{l}\text { mai./set. } 2008-8 \\
\text { eventos }\end{array}$ & $\begin{array}{l}\text { TV horizontal com vegetação } \\
\text { TV inclinado com vegetação }\end{array}$ & $\begin{array}{l}63 \%^{3} \\
25 \%^{3}\end{array}$ & Porto Alegre - RS \\
\hline $\begin{array}{l}\text { Ohnuma, Halasz e } \\
\text { Mendiondo (2011) }\end{array}$ & $3 \%$ & $\begin{array}{c}\text { set. } 2006 / \text { mar. } \\
2007-7 \text { eventos }\end{array}$ & Telhado verde (TV) & $48 \%$ & São Carlos - SP \\
\hline Baldessar (2012) & $2 \%$ & nov. 2011/ fev. 2012 & Telhado verde & $69,30 \%$ & Curitiba - PR \\
\hline Tassi et al. (2013) & $1 \%$ & $\begin{array}{c}\text { nov. } 2010 / \text { out. } \\
2011-43 \text { eventos }\end{array}$ & Telhado verde & $62 \%$ & Santa Maria - RS \\
\hline Jobim (2013) & $1 \%$ & $\begin{array}{l}\text { out. } 2012 / \text { fev. } 2013 \\
-35 \text { eventos }\end{array}$ & $\begin{array}{l}\text { Alveolar simples com argila expandida } \\
\text { Alveolar simples sem a.e. } \\
\text { Alveolar grelhado com a.e. } \\
\text { Alveolar grelhado sem a.e. } \\
\text { Reciclável com a.e. } \\
\text { Reciclável sem a.e. } \\
\text { Hexagonal com a.e. } \\
\text { Hexagonal sem a.e. } \\
\text { Modular com galocha com a.e. } \\
\text { Modular com galocha sem a.e. }\end{array}$ & $\begin{array}{r}61 \% \\
59 \% \\
61 \% \\
59 \% \\
21,7 \% \\
25,7 \% \\
79,8 \% \\
60,7 \% \\
88,1 \% \\
82,8 \% \\
\end{array}$ & Santa Maria - RS \\
\hline $\begin{array}{l}\text { Araújo et al. (2013), e } \\
\text { Araújo et al. (2014) }\end{array}$ & $15,7^{\circ}$ & mai./jun. 2012 & Telhado verde & $46,4 \%$ & Londrina - PR \\
\hline Miller (2014) & $3 \%$ & $\begin{array}{c}\text { dez. } 2013 / \text { mar. } \\
2014\end{array}$ & $\begin{array}{l}\text { Telhado verde } 1 \\
\text { Telhado verde } 2 \\
\text { Telhado verde } 3 \\
\text { Telhado verde } 4 \\
\text { Telhado verde } 5\end{array}$ & $\begin{array}{l}58,5 \% \\
47,3 \% \\
51,8 \% \\
41,9 \% \\
39,0 \%\end{array}$ & Curitiba - PR \\
\hline Savi (2015) & $3 \%$ & jun. 2014/ jan. 2015 & $\begin{array}{c}\text { TV com Bulbine } \\
\text { TV com Trapoeraba } \\
\text { TV com Grama amendoím } \\
\text { TV com Sedum } \\
\text { TV com Dinheiro em Penca }\end{array}$ & $\begin{array}{l}94 \% \\
77 \% \\
84 \% \\
88 \% \\
63 \% \\
\end{array}$ & Curitiba - PR \\
\hline Mendonça (2015) & $3 \%$ & $\begin{array}{c}\text { jan./fev. } 2015-10 \\
\text { eventos }\end{array}$ & TV com Bloco TEVA & $25,54 \%$ & João Pessoa - PB \\
\hline Ferreira (2015) & n.i. & $\begin{array}{l}\text { dez. } 2014 / \text { jan. } 2015 \\
-5 \text { eventos }\end{array}$ & Telhado verde & $81,7 \%$ & Campo Mourão - PR \\
\hline Vacari (2015) & $4 \%$ & $\begin{array}{c}\text { jan./abr. } 2015-19 \\
\text { eventos }\end{array}$ & $\begin{array}{l}\text { TV de herbácea } \\
\text { TV de consórcio } \\
\text { TV de gramínea }\end{array}$ & $\begin{array}{l}61 \% \\
59 \% \\
46 \% \\
\end{array}$ & Cuiabá - MT \\
\hline Martins e Pinto (2016) & $\begin{array}{l}1 \mathrm{a} \\
2 \%\end{array}$ & $\begin{array}{c}\text { nov. } 2015-7 \\
\text { eventos }\end{array}$ & $\begin{array}{c}\text { TV garrafa PET-solo-leiva } \\
\text { TV brita-solo-leiva } \\
\text { TV argila expandida-solo-leiva }\end{array}$ & $\begin{array}{c}65 \% \\
86,59 \% \\
80,22 \% \\
\end{array}$ & Santa Maria - RS \\
\hline Pessoa (2016) & $1^{0}$ & $\begin{array}{c}\text { fev.2015/ abr. } 2016 \\
-51 \text { eventos }\end{array}$ & $\begin{array}{l}\text { Telhado verde } \\
\text { Telado de controle }\end{array}$ & $\begin{array}{l}57 \% \\
17 \% \\
\end{array}$ & Santa Maria - RS \\
\hline Klein (2017) & $2 \%$ & $\begin{array}{l}\text { jun. } 2016 / \text { jan. } 2017 \\
-35 \text { eventos }\end{array}$ & $\begin{array}{l}\text { Telhado convencional } \\
\text { Telhado verde modular baixo } \\
\text { Telhado verde modular alto } \\
\text { Telhado verde contínuo }\end{array}$ & $\begin{array}{c}8 \% \\
76 \% \\
84 \% \\
65 \% \\
\end{array}$ & Florianópolis - SC \\
\hline
\end{tabular}

Fonte: Os autores.

Entre os fatores externos, os mais citados são:

(i) Inclinação do sistema: em geral, os autores concordam que quanto menor a inclinação utilizada, maior a capacidade de retenção obtida pelo sistema.

(ii) Umidade: vários dos trabalhos selecionados testam a capacidade de armazenamento da cobertura para diferentes graus de umidade. O solo seco apresenta maior capacidade de retenção, portanto a intensidade de precipitação, umidade atmosférica e o período de intervalo entre eventos de precipitação são grandes influentes do desempenho desses telhados. (iii) Taxa de evapotranspiração: quanto maior a taxa de evapotranspiração, melhor o desempenho hidrológico do sistema. Nascimento (2015) observa que o módulo de telhado verde não vegetado (uso apenas da camada de substrato) apresentou maior potencial de retenção de escoamento, devido a um verão excepcionalmente seco, o que expos o sistema a condições de evaporação direta (diferentemente dos telhados com vegetação, que sombrearam o substrato), influenciando o potencial de retenção do protótipo.

Já os fatores internos ao sistema são relacionados aos seus componentes. Cada camada do sistema influencia diretamente o desempenho hidrológico da cobertura. Essa 
característica explica o porquê de cada pesquisa estudar um sistema próprio, uma vez que, em um cenário nacional, ainda não existe um sistema ótimo, ou diretrizes de planejamento, execução e manutenção para telhados verdes, como existe na Alemanha, por exemplo. Diversas abordagens foram observadas entre os materiais selecionados. Em um cenário geral, dividiram-se os resultados entre experimentos que utilizaram eventos de precipitação natural, e eventos de precipitação simulados. Além disso, o período de monitoramento e a quantidade e intensidade das precipitações simuladas são únicos de cada pesquisa. $\mathrm{O}$ método utilizado para manipulação dos resultados também é variável, mas num geral, os trabalhos apresentam valores de quantidade de escoamento em porcentagem, em função do volume total precipitado.

Destaca-se que todos os telhados verdes estudados por esta revisão apresentaram algum grau de capacidade de retenção das águas pluviais por seus sistemas. Esses resultados corroboram com a teoria de que telhados verdes seriam capazes de auxiliar no tratamento de drenagens urbanas, principalmente na redução de alagamentos e enchentes. Entretanto, ainda são necessários maiores estudos na área, principalmente em busca de um sistema que compreenda características ótimas para uso em regiões brasileiras.

\section{Atraso do escoamento pluvial}

Oliveira (2009) simula dois eventos de precipitação. O primeiro evento simulado, com intensidade de precipitação de $8,77 \mathrm{~mm} / \mathrm{h}$ por um período de 13 minutos apresentou atraso do início de escoamento pluvial de 8 min, em comparação com um telhado de fibrocimento. Já o segundo evento de precipitação, com intensidade de 42 $\mathrm{mm} / \mathrm{h}$ apresentou um atraso de escoamento de $6 \mathrm{~min}$, comparado com o telhado de fibrocimento.

Santos et al. (2013) e Santos (2011) são referentes à mesma pesquisa científica. Nessa pesquisa, os autores simulam dois eventos de precipitação, o primeiro com intensidade de $42 \mathrm{~mm} / \mathrm{h}$, e o segundo de $79 \mathrm{~mm} / \mathrm{h}$, ambos com duração de $30 \mathrm{~min}$. Dois protótipos de telhados verdes são utilizados: um com uso de cacto como camada de vegetação, e outro com uso de grama. Para a primeira simulação, o retardo do início do escoamento foi de $5 \mathrm{~min}$ para o telhado com cactos, e 6 min para o telhado com grama, em comparação com um telhado convencional. Para a segunda simulação, os resultados de atraso do início do escoamento permaneceram os mesmos da primeira. Já o atraso do pico do escoamento foi de 11 min para ambos os telhados verdes na primeira simulação, 10 min para o telhado com cacto e $11 \mathrm{~min}$ para o telhado com grama na segunda simulação.

Nascimento (2015) apresenta valores médios de retardo de escoamento em telhados verdes modulares em torno de 12 min. Além disso, a autora observou que o inicio do escoamento dos módulos vegetados ocorreu mais rápido que dos módulos com apenas substrato, principalmente em condição de umidade seca.

Costa, Costa e Poleto (2012) e Costa, Poleto e Ramme (2016) desenvolvem pesquisas similares, onde utiliza-se eventos de chuva simulados para monitoramento do desempenho hidrológico de módulos de telhado verde. Em ambos os estudos os telhados retardaram o início do escoamento.

Louzada (2016) simula eventos de diferentes intensidades de precipitação com duração de 20 e 30 min para cada valor de inclinação avaliado. Quatro módulos de telhado verde foram avaliados, dois com uso de geomanta e dois com uso de geotêxtil como camada de drenagem. Os autores observam que a inclinação do sistema não influenciou no tempo de atraso início do escoamento. Os módulos com manta geotêxtil apresentaram o melhor desempenho de retardo.

Como observado, todos os estudos selecionados referentes ao atraso do início e do pico do escoamento apresentam resultados positivos, mesmo em condições com umidade. Essa característica de telhados verdes já é bastante estudada e aceita como uma vantagem característica dessas coberturas por pesquisadores internacionais.

\section{Qualidade das águas escoadas}

Segundo Vijayaraghavan, Joshi e Balasubramanian (2012), telhados verdes tem emergido como estratégia prática para melhora da qualidade ambiental de centros urbanos, entretanto, o impacto da cobertura verde na qualidade de águas pluviais permanece um tópico de preocupação para planejadores e legisladores. Altas concentrações de nutrientes, principalmente nitrogênio e fósforo em águas de escoamento podem levar a eutrofização de corpos de águas de superfície, que pode levar ao aumento da produção de algas e hipóxia (diminuição das taxas de oxigênio) devido à grande quantidade de matéria orgânica decomposta, reduzindo a qualidade da bacia hidrográfica em relação ao habitat de peixes, atividades de recreação e potabilidade da água. (WHITTINGHILL et al., 2016)

Diversos autores têm observado a presença de metais pesados e outros contaminantes nas águas escoadas por telhados verdes, em alguns casos, até mesmo em graus de poluição. A degradação da qualidade dessas águas poderia ser resultado de más escolhas de fertilizantes, substratos e vegetações utilizadas no sistema, afinal, a capacidade de fitorremediação ${ }^{2}$ nunca foi um critério de escolha para os componentes de telhados verdes. Para considerar-se telhados verdes como recursos tecnológicos ambientalmente benignos e ainda atender as expectativas de usuários, a correta seleção de componentes para o 
sistema deve ser uma prioridade (VIJAYARAGHAVAN; RAJA, 2014).

Nenhuma legislação brasileira trata especificadamente de águas pluviais escoadas por coberturas verdes, sendo, portanto, necessário buscar diretrizes alternativas para comparação da qualidade dessas águas. Observou-se que os trabalhos selecionados utilizaram bases semelhantes de normas e legislações para essa comparação. Um levantamento das diretrizes utilizadas é apresentado no Quadro 2.

Quadro 2 - Diretrizes utilizadas nos trabalhos levantados para comparação da qualidade das águas escoadas por telhados verdes

\begin{tabular}{|c|c|}
\hline Diretriz & Disposição \\
\hline ABNT NBR 13969/1997 & $\begin{array}{l}\text { Tanques sépticos - unidades de } \\
\text { tratamento complementar e disposição } \\
\text { final dos efluentes líquidos - projeto, } \\
\text { construção e operação }\end{array}$ \\
\hline ABNT NBR 15527/2007 & $\begin{array}{c}\text { Água de chuva - aproveitamento de } \\
\text { coberturas em áreas urbanas para fins } \\
\text { não potáveis - requisitos }\end{array}$ \\
\hline EMBRAPA 167 & $\begin{array}{c}\text { Qualidade de água para fins de } \\
\text { irrigação (conceitos básicos e práticos) }\end{array}$ \\
\hline $\begin{array}{l}\text { EPA (Environmental } \\
\text { Protection Agency) } 1992\end{array}$ & $\begin{array}{l}\text { Guia para reuso de águas (guidelines } \\
\text { for water reuse) }\end{array}$ \\
\hline $\begin{array}{l}\text { Portaria do Ministério da } \\
\text { Saúde } n^{0} 2.914 / 2011\end{array}$ & $\begin{array}{l}\text { Dispõe sobre os procedimentos de } \\
\text { controle e de vigilância da qualidade da } \\
\text { água para consumo humano e seu } \\
\text { padrão de potabilidade }\end{array}$ \\
\hline Resolução 128/06 RS & $\begin{array}{l}\text { Dispõe sobre a fixação de padrões de } \\
\text { emissão de efluentes líquidos para } \\
\text { fontes de emissão que lancem seus } \\
\text { efluentes em águas superficiais no } \\
\text { estado do Rio Grande do Sul }\end{array}$ \\
\hline Resoluções $n^{0} 357$ CONAMA & $\begin{array}{c}\text { Dispõe sobre a classificação dos corpos } \\
\text { de água e diretrizes ambientais para o } \\
\text { seu enquadramento, bem como } \\
\text { estabelece as condições e padrões de } \\
\text { lançamento de efluentes, e dá outras } \\
\text { providências }\end{array}$ \\
\hline Resoluções $n^{0} 400$ CONAMA & $\begin{array}{l}\text { Institui a câmara técnica recursal de } \\
\text { infrações ambientais, define sua } \\
\text { finalidade, composição e competência }\end{array}$ \\
\hline
\end{tabular}

Fonte: Os autores.

Moruzzi, Moura e Barbassa (2014) e Moura (2012) são materiais referentes à mesma pesquisa científica. Nessa pesquisa os autores avaliam a qualidade da água que passa por módulos de telhados verdes com inclinação de 10, 20 e $30 \%$. Os módulos atingiram concentrações de $\mathrm{pH}$, cor aparente e turbidez dentro do limite estipulado por legislação.

Basso (2013) analisa parâmetros de pH, turbidez, coliformes fecais e cloro residual livre, a fim de avaliar se esta água pode ser reutilizada. A autora conclui que as águas filtradas pela cobertura verde estudada estão de acordo com a legislação. Para a correção da cor amarelada da água escoada, é indicado o uso de hipoclorito de sódio $2,5 \%$ (cloro).
Budel (2014) e Teixeira et al (2017) são materiais referentes à mesma pesquisa científica. Nessa pesquisa os autores comparam a qualidade da água de chuva coletada em duas residências, uma construída com telhado verde e a outra com telhado convencional. As águas escoadas pelo telhado convencional apresentaram maior qualidade no parâmetro turbidez que no telhado verde, e seus valores de amônia, nitrato e nitrito atendem a legislação. Os dois telhados indicaram concentrações de fosfato superiores ao indicado para irrigação. O telhado verde apresentou qualidade superior no parâmetro $\mathrm{pH}$, diminuindo a acidez natural da água da chuva. Já o telhado convencional apresentou qualidade superior no parâmetro demanda química de oxigênio (DQO). Nos parâmetros microbiológicos os dois telhados não obtiveram qualidade suficiente para atender às legislações. Sendo que o telhado verde apresentou os valores mais altos para coliformes totais e termo tolerantes (Escherichia coli). Com a análise dos resultados conclui-se que para as casas avaliadas, seria necessária a instalação de um sistema de desinfecção para tratamento da água da chuva in natura e armazenada nos reservatórios.

Castro (2014), Castro e Goldenfum (2008), e Castro e Goldenfum (2010) são trabalhos referentes à mesma pesquisa científica. Nessa pesquisa, os resultados das análises físico-químicas não apresentaram diferença significativa entre os módulos planos e inclinados. Para todos os módulos avaliados, a água escoada é classificada como de possível uso para fins não potáveis. Em comparação com o módulo sem camada de vegetação (apenas substrato), o telhado vegetado apresentou uma qualidade inferior. Essa diferença é explicada pela presença da vegetação, que aumenta os valores de sólidos totais, fósforo total, nitrogênio, nitrato, turbidez, DBO (demanda bioquímica de oxigênio), e transformou o $\mathrm{pH}$ em alcalino. Segundo os autores, é necessário tratamento antes do uso dessas águas.

Savi (2015) avalia a qualidade da água escoada por coberturas verdes através dos parâmetros de $\mathrm{pH}$, nitrogênio total, nitrogênio amoniacal, fósforo total, coloração e sólidos totais. Valores elevados de concentração de fósforo e nitrogênio foram identificados. A coloração da água escoada apresentou tom ferroso intenso, superior aos valores máximos previstos na legislação e superior à da água escoada por coberturas tradicionais. A quantidade de total de sólidos dissolvidos presentes e $\mathrm{pH}$ ficaram dentro dos parâmetros previstos pela legislação, tanto para ambos os telhados.

Para Ferreira (2015) a água escoada pelo telhado verde atendeu aos valores de legislação nos parâmetros de turbidez, cor e $\mathrm{pH}$. Entretanto, valores de coliformes totais foram observados, quando estes deveriam ser ausentes. Já para a cobertura de fibrocimento, valores de coliformes 
termotolerantes e totais não foram observados. Os parâmetros de cor, turbidez e $\mathrm{pH}$ analisados também atendem a legislação. Assim, a água escoada por essa cobertura poderia ser utilizada para fins não potáveis.

Para Vacari (2015) a água escoada por telhados verdes apresentou maior concentração de cor verdadeira e turbidez, esse valor provavelmente se deve pela presença de concentrações de sólidos totais provenientes do substrato. As concentrações de DBO, bactérias heterotróficas e fungos cultiváveis não apresentaram diferenças entre telhado convencional e telhados verdes. Já as concentrações de coliformes totais nos telhados verdes apresentaram valores superiores ao telhado convencional, entretanto, o contrário ocorreu em relação à Escherichia coli. Os telhados verdes atuaram como contaminantes de todos os nutrientes avaliados (sulfato, nitrogênio amoniacal e nitrato e ortofosfato). Já o telhado de fibrocimento atuou como sumidouro de ortofosfato.

Pessoa (2016) avalia parâmetros físicos (turbidez, cor aparente, cor verdadeira, condutividade elétrica, sólidos totais, sólidos dissolvidos, sólidos suspensos e temperatura). Parâmetros químicos ( $\mathrm{pH}$, fosfato, nitrogênio total, nitrato, nitrito, cloretos, sulfatos, DBO e dureza). Presença de metais (cobre, ferro, zinco, chumbo e cromo). E por fim, parâmetros microbiológicos (coliformes totais E. coli). Os telhados verdes comportaram-se como fonte poluidora de parâmetros físicos, químicos e microrganismos.

Klein (2017) avalia a qualidade de água escoada por três protótipos de telhado verde, um de cobertura convencional, e água pluvial captada. A cobertura verde modular alta atuou como fonte de cor, ferro, nitrato, fósforo, fosfato e coliformes. A cobertura verde modular baixa apresentou comportamento semelhante, com aumento dos níveis de turbidez da água da chuva. O pior comportamento foi observado na cobertura verde contínua, que também se comportou como fonte de nitrito. A cobertura convencional comportou-se como fonte de cor, ferro, nitrito, nitrato e coliformes. Com exceção da cobertura verde modular baixa, a passagem da água da chuva pelas demais coberturas aumentou significativamente o valor de $\mathrm{pH}$. O escoamento da cobertura verde contínua apresentou a maior quantidade de poluentes. Os teores de turbidez, cor aparente, ferro, nitrito, fósforo, fosfato e coliformes termotolerantes foram significativamente maiores na água escoada por essa cobertura, o que indica que a maior quantidade de substrato provocou maior liberação destes parâmetros no escoamento. Nenhuma das coberturas atendeu aos limites impostos por legislação. Assim, essas águas precisariam de tratamento prévio antes de seguirem para a rede de abastecimento, ou serem reutilizadas.
Observa-se uma divergência nos resultados levantados quanto a qualidade das águas de escoamento. Para alguns estudos, essas estariam dentro de padrões estipulados por legislação, para outros estudos apresenta-se a necessidade de tratamento antes do reuso das mesmas. Entretanto, no geral, algumas considerações são apresentadas por mais que um autor:

(i) A inclinação do sistema não parece influenciar na quantidade de sólidos dissolvidos suspensos lixiviados pelo sistema.

(ii) Concentrações elevadas de substâncias como fosfato, fósforo, nitrogênio, ferro e nitrito são relacionadas à lixiviação de componentes presentes na camada de substrato, ou da adubação do sistema.

(iii) Telhados convencionais ou telhados verdes sem a camada de vegetação (apenas com substrato) tendem a apresentar qualidade superior nos parâmetros de sólidos totais, fósforo total, nitrogênio, nitrato, turbidez e DBO, comparando com telhados verdes. Isso é resultado da menor concentração de matéria orgânica (vegetação) em decomposição nesses sistemas.

Estudos voltados para a qualidade das águas escoadas por telhados verdes é uma linha relativamente nova de pesquisa, tanto em um cenário nacional quanto internacional. Inúmeras variáveis externas e internas parecem afetar o desempenho qualitativo desses sistemas, sendo necessário maiores estudos antes da efetiva disseminação dessa tecnologia construtiva.

\section{Características e composição do substrato}

Uma abordagem ao estudo do desempenho hidrológico de telhados verde é avaliar composições, características e desempenho de substratos para uso específico nessas coberturas, buscando melhorar a capacidade de retenção hídrica e retardo do pico de escoamento de águas pluviais.

Oliveira (2012) testa substratos compostos com cinco diferentes granulometrias de palha de coco. Para precipitações leves, os substratos apresentaram taxa de retenção de 60 a $100 \%$ do total precipitado. Já para precipitações elevadas, a faixa de retenção ficou entre 40 e 59\%. Análises físicas e de qualidade da água escoada que passa pelo substrato também foram realizadas. As composições de substratos estudadas atenderam seu objetivo referente à retenção hídrica, entretanto, a qualidade da água percolada tornou seu uso inviável.

Willes (2014) estuda 5 tipos de substratos mono componentes e 5 tipos de substratos compostos comerciais. Foram realizados ensaios de caracterização física e química. O mono composto de turfa marrom apresentou o menor valor de densidade seca, maior porosidade total, maiores valores de água facilmente 
disponível, água disponível, capacidade de retenção de água e valor de espaço de aeração dentro dos padrões ótimos. Dos substratos comerciais selecionados, o substrato para espécies hortícolas apresentou os maiores valores de capacidade de retenção de água e água disponível para vegetação, o que possibilita maior intervalo entre irrigações ou chuvas.

Garcia et al. (2015) testam o uso de 3 substratos: BIOMIX, fibra de casca de coco verde e fibra bagaço da cana-deaçúcar. Os resultados obtidos apresentam que todos materiais estudados foram eficientes no controle do escoamento. Embora o substrato comercial tenha sido o mais eficiente em relação a redução e retardo do escoamento, e diminuição da vazão de pico, os materiais fibrosos, além de também apresentarem impacto positivo no controle do escoamento, possibilitam o uso desses resíduos, contribuindo na redução dos mesmos no meio ambiente.

Magalhães (2015) executa testes de percolação e qualidade da água em uma composição de substrato e condicionadores para uso em telhados. O uso do gel promoveu aumento significativo na retenção hídrica, e adiou o início do escoamento da água, além de promover aumento do $\mathrm{pH}$ da mesma. A adição de zeólita aumentou significativamente a retenção hídrica, entretanto o custo extra deste composto torna seu uso não vantajoso. A adição de fertilizante de liberação lenta não promoveu mudanças na qualidade da água percolada. A presença desses condicionadores no substrato melhorou o desempenho para as características avaliadas. Uma vez que o uso de fertilizante escoou alta concentração de nutrientes (nitrogênio e fósforo) para a água percolada, o autor recomenda, entre as três opções, o uso do gel como condicionante para uso em telhados verdes.

Poucas pesquisas brasileiras relacionadas às condições ótimas para substratos em telhados verdes foram encontradas. Esse tipo de abordagem se torna interessante, uma vez que, a concentração de esforços em um componente especifico possa gerar maiores resultados para características ideais dos mesmos, que estudos que considerem o sistema como um todo.

\section{Simulações de implementação}

Esses estudos buscam simular o impacto do uso de telhados verdes no volume de águas pluviais escoadas para as áreas de drenagem.

Calil, Bernardi e Righes (2014) simulam o impacto do uso de telhados verdes na micro bacia urbana do Arroio Esperança, em Santa Maria - RS. Para o cenário estabelecido, os autores previram uma redução do pico de vazão em $35,4 \%$, e uma diminuição do coeficiente médio de deflúvio da bacia de 0,53 para 0,35. Estima-se que telhados verdes com grama e $20 \mathrm{~cm}$ de camada de solo do tipo argissolo vermelho distrófico arênico seriam capazes de reter até $58,61 \mathrm{~mm}$ de precipitação pluviométrica.

Vieira, Silva Jr. e Ribeiro (2015) simulam a substituição de telhados convencionais por telhados verdes em diferentes edificações. Cinco escolas, seis terminais de integração e a cobertura das garagens do Condomínio Residencial Mar de Aruana II foram selecionados para estudo, todos localizados na cidade de Aracaju- SE. A simulação indicou uma redução do volume anual escoado para a rede de drenagem urbana de $10302,16 \mathrm{~m}^{3}$ nas escolas, 5836,24 $\mathrm{m}^{3}$ nos terminais de integração, e de $2005,46 \mathrm{~m}^{3}$ na cobertura das garagens. Os autores concluíram que o uso de telhados verdes poderia contribuir satisfatoriamente com a redução das enchentes urbanas, desde que seu uso seja coletivo e inserido na urbanização das cidades.

Garrido Neto (2016) simula o impacto da adoção de telhados verdes na Bacia do Rio Joana - RJ. Considerando-se apenas a capacidade de reter escoamento superficial, constata-se que a influência dessas coberturas seria pequena, para o cenário estabelecido. Segundo o autor, a bacia de estudo é uma área crítica, devido à alta intensidade de ocupação e subdimensionamento atual das redes de drenagem, torando-se uma área suscetível de inundações. Sendo assim, o uso de telhados verdes funcionaria como uma medida de apoio para uma drenagem urbana sustentável. Por fim, acredita-se que o efeito dessas coberturas na bacia seria potencializado ao considerar-se os atrasos do início do escoamento superficial promovido pelo uso das mesmas, e se seu uso fosse expandido para telhados já existentes.

Alamy Filho et al. (2016) simulam o impacto da implantação de telhados verdes em edificações de um condomínio residencial situado em Uberlândia - MG. Os autores estimaram uma eficiência de retenção máxima global de 55,67\% para condições de solo seco, usuais após períodos de estiagens. Estimou-se uma eficiência média de $40,35 \%$. Entretanto, essa eficiência é reduzida para $29,05 \%$ em condição de umidade normal do solo, chegando em 10,44\% em condições de saturação.

Leite, Fujimura e Fernandes (2016) simulam o impacto da implantação de telhados verdes na construção da Universidade Federal de Mato Grosso, campus Cuiabá, e comparam com o cenário atual. Os resultados apresentam redução em $18 \%$ o pico do coeficiente de escoamento superficial com a utilização de telhados verdes. Portanto, esta técnica compensatória poderia ser uma solução para os pontos de alagamentos que ocorrem no Campus UFMT.

Embora poucos estudos tenham sido encontrados nessa área de pesquisa, todos os resultados levantados apresentam algum grau de benefício na implantação de telhados verdes, em escalas de loteamento. Entretanto, a 
falta de materiais na área indica a necessidade de maiores estudos para resultados mais sólidos.

\section{Conclusão}

As referências bibliográficas selecionadas nesta revisão sistemática permitem observar que, embora a frequência de estudos relativos às condições hidrológicas de telhados verdes tenha aumentado nos últimos anos, a quantidade de estudos ainda é insuficiente para tirar-se evidências científicas efetivas quanto ao desempenho desses sistemas no Brasil. A grande variedade de métodos e abordagens dificulta a comparação dos resultados levantados quanto a capacidade de telhados verdes reterem volume de precipitação em seus sistemas. Entretanto, a maioria dos autores concorda que aspectos como inclinação, umidade, período de intervalo e características da precipitação afetam diretamente no desempenho do sistema. Esses estudos vão ao encontro de pesquisas internacionais, onde o desempenho de redução de escoamento já é considerado como uma das principais características de telhados verdes. Alguns trabalhos internacionais que corroboram com os resultados levantados podem ser encontrados na revisão sistemática realizada por Berndtsson (2010), que também faz um levantamento de vários aspectos relacionados ao comportamento hidrológico de telhados verdes, em um cenário internacional. Os componentes utilizados para a construção do telhado também são de vital importância para seu desempenho. No geral, concorda-se que o componente de maior influência estudado até o momento é a camada de substrato. Por essa mesma razão, algumas pesquisas se voltam para estudos específicos deste componente.

Quanto à qualidade das águas escoadas, a maioria dos estudos também destacam a influência do substrato, que tende a lixiviar nutrientes e partículas. Os resultados levantados nesse item são particularmente controversos, uma vez que cada estudo apresentou resultados únicos. Pesquisas internacionais têm investido esforços para aumentar o conhecimento quanto ao desempenho da qualidade das águas que são escoadas por telhados verdes. Estes estudos são recentes, com os primeiros trabalhos datados na década de 2000. Portanto, ainda se buscam sistemas otimizados, capazes de gerar menos lixiviação de substâncias, como em Malcolm et al. (2014), onde os autores testam o uso de bolsas de alume na camada de substrato, e obtém uma redução de $22 \%$ das concentrações de fósforo escoadas. Vijayaraghavan e Joshi (2015) testam o uso de algas marrons em substratos, apresentando um bom desempenho de redução de metais pesados lixiviados.

As simulações de implantação de telhados verdes em escala de loteamentos também apresentaram resultados controversos. Isso se deve provavelmente às condições de área utilizadas para análise. Entretanto, todos observam algum grau de melhora nas condições de drenagem com a adoção dessas coberturas.

Esta revisão destaca a necessidade de maiores estudos quanto ao desempenho quantitativo e qualitativo do escoamento de telhados verdes, e sua influência em sistemas de drenagem urbana. Também se observa que métodos de pesquisa padronizados (como padronização dos resultados de escoamento em uma mesma unidade, como porcentagem ou milímetros, ou definir ensaios padrões de qualidade das águas, entre outros) poderiam ser uma solução interessante para os problemas de compatibilização de resultados, e poderiam contribuir de maneira positiva na construção de uma evidência cientifica da adaptação e desempenho dessas coberturas para regiões brasileiras.

Sugere-se que futuras pesquisas busquem estudar sistemas otimizados para cada região, como substratos, vegetações e materiais drenantes que se adaptem às condições locais, e lixiviem uma menor concentração de poluentes. Por fim, grande atenção deve ser voltada à análise de qualidade das águas escoadas por telhados verdes, uma vez que ainda não se sabe se a adoção destas coberturas em grandes áreas construídas poderia, ou não, vir a afetar negativamente corpos d'água próximos a essas edificações.

\section{Agradecimentos}

Os autores agradecem a concessão de bolsa para a primeira autora, promovida pela Coordenação de Aperfeiçoamento de Pessoal de Nível Superior (CAPES), e ao apoio da Universidade Federal do Paraná (UFPR).

\section{Notas}

(1) Não identificado no material.

(2) Utilização de plantas para a extração/amenização de compostos poluentes de solos (VASCONCELLOS; PAGLIUSO; SOTOMAIOR, 2012).

(3) Valores referentes a 12 horas após o início dos eventos de precipitação estudados. 


\section{Referências}

ALAMY FILHO, José Eduardo; et al. Eficiência hidrológica de telhados verdes para a escala de loteamentos residenciais. Sociedade e Natureza. Uberlândia, v. 28, n. 2, p. 257 - 272, mai. /ago. 2016. http://dx.doi.org/10.1590/1982-451320160206

ALEXANDRI, E.; JONES, P. Temperature decreases in an urban canyon due to green walls and green roofs in diverse climates. Building and Environment. [S.I] v. 43, n. 4, p. 480 - 493. Abril. 2008. http://doi.org/10.1016/j.buildenv.2006.10.055

ARAÚJO, A. P. C. S. et al. Aproveitamento de água pluvial em sistema modular de telhado verde com aplicação em sistemas de drenagem urbana. In: INTERNATIONAL WORKSHOP ADVANCES IN CLEANER PRODUCTION, 4., 2013 , São Paulo. Anais... São Paulo: [ s.n.], 2013, On-line.

ARAÚJO, A. P. C. S. et al. Balanço hídrico de sistema modular para telhado verde. Enciclopédia biosfera, Centro Científico Conhecer. Goiânia, v. 10, n. 18; p. 637 - 644, jul. 2014.

BACOVIS, Tiago Martins; NAGALLI, André. Avaliação do desempenho hidrológico de protótipo de telhado verde extensivo. Rev. Acad., Ciênc. Agrár. Ambient., Curitiba, v. 11, Supl. 1, p. S35-S42, 2013. http://doi.org/10.7213/academica.10.S01.A

BALDESSAR, Silvia Maria Nogueira. Telhado verde e sua contribuição na redução da vazão da água pluvial escoada. 2012. 125 f. Dissertação (Mestrado em Engenharia da Construção Civil) - Universidade Federal do Paraná, Curitiba, 2012.

BASSO, Anelise. Cobertura verde como sistema de reaproveitamento de água da chuva e águas servidas. $2013.57 \mathrm{f}$. Trabalho de conclusão de curso - Universidade Tecnológica Federal do Paraná, Pato Branco, 2013.

BERARDI, Umberto; GHAFFARIANHOSEINI, AmirHosein; GHAFFARIANHOSEINI, Ali. State-of-the-art analysis of the environmental benefits of green roofs. Applied Energy, [S.I.], v. 115, p. 411 - 428, fev. 2014. http://doi.org/10.1016/j.apenergy.2013.10.047

BERNDTSSON, J. C. Green roof performance towards management of runoff water quantity and quality: A review. Ecological Engineering. [S.I.], v. 36, p. 351 - 360, abril, 2010. http://doi.org/10.1016/j.ecoleng.2009.12.014

BRASIL. Ministério da Saúde. Secretaria de Ciência, Tecnologia e Insumos Estratégicos. Departamento de Ciência e Tecnologia. Diretrizes metodológicas: elaboração de revisão sistemática e metanálise de ensaios clínicos randomizados/ Ministério da Saúde, Secretaria de Ciência, Tecnologia e Insumos Estratégicos, Departamento de Ciência e Tecnologia. - Brasília: Editora do Ministério da Saúde, 2012. 92 p.: il. - (Série A: Normas e Manuais Técnicos).

BRASIL. Ministério do Planejamento, Orçamento e Gestão. Instituto Brasileiro de Geografia e Estatística - IBGE. Diretoria de Pesquisas. Coordenação de População e Indicadores Sociais. Pesquisa de Informações Básicas Municipais. Perfil dos Municípios Brasileiros 2013/ Ministério do Planejamento, Orçamento e Gestão. Instituto Brasileiro de Geografia e Estatística - IBGE. Diretoria de Pesquisas - Rio de Janeiro: Editora do Instituto Brasileiro de Geografia e Estatística - IBGE, 2013.

BUDEL, Marcel Aramis. Estudo comparativo da qualidade da água de chuva coletada em cobertura convencional e em telhado verde. 2014. 125 f. Dissertação (Mestrado em Engenharia Civil) - Universidade Tecnológica Federal do Paraná, Curitiba, 2014.

CALIL, Vitor da Silva; BERNARDI, Ewerthon Cezar Schiavo; RIGHES, Afranio Almir. Impacto da utilização de telhados verdes no escoamento superficial do arroio esperança em Santa Maria-RS. Disciplinarum Scientia. Série: Naturais e Tecnológicas, Santa Maria, v. 15, n. 1, p. 1-16, 2014.

CASTRO, Andréa Souza. Uso de pavimentos permeáveis e coberturas verdes no controle quali-quantitativo do escoamento superficial urbano. 2011. 142 f. Tese (Doutorado em Recursos Hídricos e Saneamento Ambiental) - Universidade Federal do Rio Grande do Sul, Porto Alegre, 2011.

CASTRO, Andréa Souza; GOLDENFUM, J. A. Uso de telhados verdes no controle quali-quantitativo do escoamento superficial urbano. In: ENCONTRO NACIONAL DE ÁGUAS URBANAS e VI ENCONTRO FRANCO-BRASILEIRO EM HIDROLOGIA URBANA, VIII, 2008, Rio de Janeiro. Anais... Rio de Janeiro, 2008.

CASTRO, Andréa Souza; GOLDENFUM; Joel Avruch. Uso de telhados verdes no controle quantitativo do escoamento superficial urbano. Revista Atitude. 2010, Porto Alegre, Ano IV, n. 7, p. 75 - 81, jan./ jun. 2010. 
COSTA, Jefferson da; COSTA, Anderson; POLETO, Cristiano. Telhado verde: redução e retardo do escoamento superficial. Revista de estudos ambientais. [S.I.], v. 14, n. 2, p. 50-56. 2012. http://dx.doi.org/10.7867/1983-1501.2012v14n2p49-55

COSTA, Jefferson da; POLETO, Cristiano; RAMME, Silvana da Silva. Redução e retardo do escoamento superficial das águas pluviais em telhado verde. In: ENCONTRO DE INICIAÇÃO CIENTÍFICA. 4., 2016, Toledo. Anais... Toledo, [ s.n.], 2016.

FERREIRA, Lucas Augusto Prudente. Análise comparativa do atraso no escoamento, e da quantidade e qualidade de água pluvial escoada em telhado verde extensivo e de fibrocimento. 2015. $44 \mathrm{f}$. Trabalho de conclusão de curso - Universidade Tecnológica Federal do Paraná, Campo Mourão, 2015.

\section{FLL FORSCHUNGSGESELLSCHAFT LANDSCHAFTSENTWICKLUNG LANDSCHAFTSBAU E.V.. Guidelines for} planning execution and upkeep of Green roof sites. 2 ed. Bonn: FLL, 2002. p. 95.

GARCIA, Bruno Antônio Scatolin Rossafa et al. Análise do runoff a partir de materiais vegetais residuais fibrosos para uso como substrato agrícola em telhados verdes. In: SIMPÓSIO BRASILEIRO DE RECURSOS HÍDRICOS. 21., 2015, Brasília. Anais... São Paulo, [ s.n.], 2015. Disponível em: < http://www.evolvedoc.com.br/sbrh/detalhes-1142 analise-do-runoff-a-partir-de-materiaisvegetais-residuais-fibrosos-para-uso-como-substrato-agricola-em-telhados-verdes $>$. Acesso em: 17/03/2018.

GARRIDO NETO, Pedro de Souza. Telhados verdes como técnica compensatória em drenagem urbana na cidade do rio de janeiro: estudo experimental e avaliação de sua adoção na bacia do rio joana a partir do uso de modelagem matemática. 2016.321 f. Dissertação (Mestrado em Engenharia Civil) - Instituto Alberto Luiz Coimbra de Pós-Graduação e Pesquisa de Engenharia, Rio de Janeiro, 2016.

JOBIM, Alan Lamberti. Diferentes tipos de telhados verdes no controle quantitativo da água pluvial. 2013.75 f. Dissertação (Mestrado em Engenharia Civil) - Universidade Federal de Santa Maria, Santa Maria, 2013.

KLEIN, Lais de Bortoli. Controle qualitativo e quantitativo do escoamento pluvial em diferentes tipos de coberturas. 2017. 181 f. Dissertação (Mestrado em Engenharia Civil) - Universidade Federal de Santa Catarina, Florianópolis, 2017.

LAMERA, C. et al. Green roofs effects on the urban water cycle components. Procedia Engineering. [S.I], v. 70 , p. 988 - 997. 2014. http://doi.org/10.1016/j.proeng.2014.02.110

LEITE, Bruna Pereira; FUJIMURA, Jéssika Mayumi; FERNANDES, Jhenifer Stéfani de Araújo. Avaliação dos impactos na drenagem com a implantação de telhados verdes na UFMT - Campus Cuiabá utilizando o software SWMM. In: SIMPÓSIO DE GEOTECNOLOGIAS NO PANTANAL. 6., 2016, Cuiabá. Anais... Embrapa Informática Agropecuária/INPE, p. $354-363$.

LOUZADA, Thiago de Souza. Emprego de geossintéticos na construção de telhados verdes: análise da capacidade de retenção de água. 2016. 94 f. Dissertação (Mestrado em Engenharia Civil) - Universidade Federal do Rio Grande do Norte, Natal, 2016.

MAGALHÃES, Francisca Rodrigues. Avaliação de condicionadores em solo para uso em telhados verdes com vistas à retenção hídrica. 2015. 108 f. Dissertação (Mestrado em Engenharia Ambiental) - Universidade do Estado do Rio de Janeiro, Rio de Janeiro, 2015.

MALCOLM, Elizabeth G.; et al. Measurements of nutrients and mercury in green roof and gravel roof runoff. Ecological Engineering. [S.I.], v. 73, p. 705 - 712, dez. 2014. http://doi.org/10.1016/j.ecoleng.2014.09.030

MARTINS, Larissa Schwengber; PINTO, Juliane dos Santos. Avaliação quali-quantitativa de telhado verde extensivo em escala piloto. Disciplinarum Scientia. Série: Naturais e Tecnológicas, Santa Maria, v. 17, n. 2, p. 245-257, 2016.

MENDONÇA, Tatyane Nadja Martins de. Telhado verde extensivo em pré-moldado de concreto EVA (Acetato Etil Vinila). 2015. 210 f. Dissertação (Mestrado em Engenharia Civil e Ambiental) - Universidade Federal da Paraíba, João Pessoa, 2015.

MENDONÇA, Tatyane Nadja Martins; MELO, Aluísio Braz de. Telhado verde modular extensivo: biodiversidade e adaptação das plantas aos Blocos TEVA.PARC Pesquisa em Arquitetura e Construção, Campinas, SP, v. 8, n. 2, p. 117-126, jun. 2017. ISSN 1980-6809. doi:http://dx.doi.org/10.20396/parc.v8i2.8649606

MILLER, Ana Priscilla Romero Rodrigues. Análise do comportamento de substrato para retenção de água pluvial para coberturas verdes extensivas em Curitiba - PR. 2014. 93 f._Dissertação (Mestrado em Engenharia da Construção Civil) Universidade Federal do Paraná, Curitiba, 2014. 
MOHER, D. et al. Preferred reporting items for systematic reviews and meta-analyses: the PRISMA statement. Tradução de Taís Freire Galvão e Thais de Souza Andrade Pansani. Retro-traduzido David Harrad. Epidemiol. Serv. Saúde, Brasília, v. 24, n. 2, p. 355 - 342, abr/jun. 2015. http://doi.org/ 10.1371/journal.pmed.1000097

MONTANARI, Ketlin Bruna; LABAKI, Lucila Chebel. Comportamento térmico de ambientes internos sob a influência de envoltórias verdes. PARC Pesquisa em Arquitetura e Construção, Campinas, SP, v. 8, n. 3, p. 181-193, set. 2017. ISSN 19806809. doi:http://dx.doi.org/10.20396/parc.v8i3.8650241

MORUZZI, R. B.; MOURA, C. C. de; BARBASSA, A. P. Avaliação do efeito da inclinação e umidade antecedente na qualidade e quantidade das parcelas escoadas, percoladas e armazenadas em telhado verde extensivo. Ambiente Construído, Porto Alegre, v. 14, n. 3, p. 59-73, jul./set. 2014.

MOURA, Cinthia Cristine de. Avaliação quali-quantitativa das parcelas escoadas, percoladas e armazenadas em instalação experimental piloto de telhado verde extensivo com diferentes inclinações. 2012. $61 \mathrm{f}$. Trabalho de formatura - Universidade Estadual Paulista “Julio De Mesquita Filho”, Rio Claro, 2012.

NASCIMENTO, Claudia Maria Loiola do. Avaliação das relações chuva-vazão em telhados verdes modulares sob chuva simulada induzida. 2015. 128 f. Dissertação (Mestrado em Engenharia Civil e Ambiental) - Universidade do Estado do Rio de Janeiro, Rio de Janeiro, 2015.

OHNUMA JÚNIOR, Alfredo Akira; HALASZ, Marcos Roberto Teixeira; MENDIONDO, Eduardo Mario. Monitoramento das águas subsuperficiais em telhados verdes como medida sustentável de combate à poluição hídrica. In: ENCONTRO LATINOAMERICANO SOBRE EDIFICAÇÕES E COMUNIDADES SUSTENTÁVEIS, 4., Vitória, 2011. Anais... Vitória, 2011. Disponível em: < http://www.elecs2013.ufpr.br/anais-elecs-2011/>. Acesso em: 17/03/2018.

OLIVEIRA, Eric Watson Netto de. Telhados verdes para habitações de interesse social: retenção das águas pluviais e conforto térmico. 2009. 87 f. Dissertação (Mestrado em Engenharia Ambiental) - Universidade do Estado do Rio de Janeiro, Rio de Janeiro, 2009.

OLIVEIRA, Clooer Costa de. Substrato para uso em telhados verdes: avaliação da retenção hídrica e qualidade da água de escoamento. 2012. 117 f. Dissertação (Mestrado em Engenharia Ambiental) - Universidade do Estado do Rio de Janeiro, Rio de Janeiro, 2012.

PESSOA, Jonas Onis. Quantidade e qualidade de águas pluviais escoadas a partir de telhados verdes extensivos em Santa Maria - RS. 2016. 159 f. Dissertação (Mestrado em Engenharia Ambiental) - Universidade Federal de Santa Maria, Santa Maria, 2016.

SANTOS, Pedro Tyaquiçã da Silva. Balanço hídrico em teto com cobertura vegetal no seminário Pernambucano. 2011. ? f. Dissertação (Mestrado em Engenharia Civil) - Universidade Federal de Pernambuco, Recife, 2011.

SANTOS, Pedro Tyaquiçã da Silva et al. Telhado verde: desempenho do sistema construtivo na redução do escoamento superficial. Ambiente Construído, Porto Alegre, v. v. 13, n. 1, p. 161-174, jan./mar. 2013.

SAVI, Adriane Cordoni. Telhados verdes: uma análise da influência das espécies vegetais no seu desempenho na cidade de Curitiba. 2015. 176 f._Dissertação (Mestrado em Engenharia da Construção Civil) - Universidade Federal do Paraná, Curitiba, 2015.

SILVA, Thomas Fernandes da; PAIVA, Anderson Luiz Ribeiro de; SANTOS, Sylvana Melo dos. Capacidade de retenção de água em um telhado verde: Estudo de caso em Caruaru. In: SIMPÓSIO BRASILEIRO DE RECURSOS HÍDRICOS. 21., 2015, Brasília. Anais... São Paulo, [ s.n.], 2015. Disponível em: http://www.evolvedoc.com.br/sbrh/detalhes-791_capacidade-de-retencao-de-aguaem-um-telhado-verde-estudo-de-caso-em-caruaru>. Acesso em: 17/03/2018.

STOVIN, Virginia; VESUVIANO, Gianni; KASMIN, Hartini. The hydrological performance of a green roof test bed under UK climatic conditions. Journal of Hydrology. [S.I.], v. 414, p. 148 - 161, jan. 2012. http://doi.org/10.1016/j.jhydrol.2011.10.022

TASSI, R.; TASSINARI, L. C. da S.; PICCILLI, D. G. A.; PERSCH, C. G. Telhado verde: uma alternativa sustentável para a gestão das águas pluviais. Ambiente Construído, Porto Alegre, v. 14, n. 1, p. 139-154, jan./mar. 2014. 
TEIXEIRA, C. A. et al. Estudo comparativo da qualidade da água da chuva coletada em telhado com telhas de concreto e em telhado verde para usos não potáveis. Ambiente Construído, Porto Alegre, v. 17, n. 2, p. 135-155, abr./jun. 2017. http://dx.doi.org/10.1590/s1678-86212017000200150

VACARI, Thaisa Camila. Caracterização da qualidade da água pluvial retida em módulos experimentais de telhados verdes e o seu estudo como alternativa tecnológica para redução do volume da água pluvial escoada. 2015. 66 f. Dissertação (Mestrado em Recursos Hídricos) - Universidade Federal de Mato Grosso, Cuiabá, 2015.

VASCONCELLOS, M. C.; PAGLIUSO, Débora; SOTOMAIOR, Vanessa S. Fitorremediação: Uma proposta de descontaminação do solo. Estudos de Biologia: Ambiente e Diversidade, [S.I], v. 34, p. 261 - 267, jul. /dez. 2012.

http://dx.doi.org/10.7213/estud.biol.7338

VIEIRA, Zacarias Caetano; SILVA JUNIOR, Carlos Gomes da; RIBEIRO, Silvana Nóbrega. Uso de telhados verdes em edificações de Aracajú para redução do escoamento superficial. In: CONGRESSO INTERNACIONAL GESTÃO DA ÁGUA E MONITORAMENTO AMBIENTAL. 2., 2015, Aracaju. Anais...Aracaju: [ s.n.], 2015, On-line.

VIJAYARAGHAVAN, K. Green roofs: A critical review on the role of components, benefits, limitations and trends. Renewable and Sustainable Energy Reviews, [S.I] v. 57, p. 740 - 752, maio. 2016. https://doi.org/10.1016/j.rser.2015.12.119

VIJAYARAGHAVAN, K.; RAJA, Franklin D. Design and development of green roof substrate to improve runoff water quality: Plant growth experiments and adsorption. Water Research, [S.I.], v. 63, p. 94 - 101, out. 2014.

http://doi.org/10.1016/j.watres.2014.06.012

VIJAYARAGHAVAN, K.; JOSHI, U. M. Application of seaweed as substrate additive in green roofs: Enhancement of water retention and sorption capacity. Landscape and Urban Planning. [S.I.], v.143, p. 25 - 32, jun. 2015.

http://doi.org/10.1016/j.landurbplan.2015.06.006

VIJAYARAGHAVAN, K.; JOSHI, U. M.; BALASUBRAMANIAN, R. A field study to evaluate runoff quality from green roofs. Water research. [S.I.], v. 46, p. 1337 - 1345, mar. 2012. http://doi.org/10.1016/j.watres.2011.12.050

WHITTINGHILL, Leigh J.; et al. Stormwater performance of a full scale rooftop farm: Runoff water quality. Ecological Engineering. [S.I.], v. 91, p. 195 - 206, jun. 2016. http://doi.org/ 10.1016/j.ecoleng.2016.01.047

WILLES, Jorge Alex. Tecnologias em telhados verdes extensivos: meios de cultura, caracterização hidrológica e sustentabilidade do sistema. 2014. 69 f. Tese (Doutorado em Ciências) - Universidade de São Paulo, Piracicaba, 2014.

\footnotetext{
${ }^{1}$ Bruna Vogt Bär

Engenheira Civil. Bacharel. Mestranda no programa de Pós Graduação em Engenharia da Construção Civil na Universidade Federal do Paraná. Endereço Postal: Evaristo F. F. da Costa, 418 - Jardim das Américas, Curitiba - PR, 80050-540

\section{${ }^{2}$ Sergio Fernando Tavares}

Arquiteto e urbanista. PhD. Professor Titular da Universidade Federal do Paraná no Departamento de Arquitetura e Urbanismo e no Programa de Pós Graduação em Engenharia da Construção Civil. Endereço Postal: Rua Schiller, 555 - Cristo Rei, Curitiba - PR, $80050-260$
} 